\title{
AVAILMENT OF FUNERAL PLANNING MANAGEMENT SERVICE AMONG CHINESE AND FILIPINO: PREPARATION OF A SERVICE DEVELOPMENT PACKAGE FOR A FUNERAL EVENT BUSINESS
}

\author{
Jojo M. Villamin. Far Eastern University. Manila \\ jvillamin@feu.edu.ph
}

\begin{abstract}
The funeral industry has grown rapidly over the years. It is very evident that in the Philippines, many funeral parlors are sprouting all over the country as well funeral insurance policy companies. The funeral industry has taken more major roles in the burial rituals, funeral arrangements, body disposition procedures, last rites, and after care services to attend to the special needs. One of the richest customs in celebrating a funeral event was the Chinese society. Chinese was well known for their custom of following a lot of superstitions. Filipinos also believed in superstitions like the Chinese, but their way of celebrating the funeral rites was different. These customs make managing a funeral event difficult. That is why seeking professional guidance and support is a good idea. The study looks into the comparative study of the availment of the funeral planning management service among Chinese and Filipino to observe the difference and similarities on the level of awareness, interest, the desire and actions of the two different cultures regarding the funeral planning management service. The researcher's purpose was to make a basis for developing an event strategy that would facilitate the acceptability of the funeral planning management service in the Philippines.
\end{abstract}

Keywords: event strategy, awareness, customs, funeral management planning service, Chinese, Filipino

\section{Introduction}

Over the years, the funeral industry has grown rapidly and has become a necessity for individuals to prepare and accept the fact that it is inevitable. Usually, people do not want to talk about it or think about it. It is usually addressed as a preneed industry because of the fact that it is something that no individual can foresee his or her time in this world. The funeral industry has taken more major roles in the burial rituals, funeral arrangements, body disposition procedures, last rites, and after care services to attend to the special needs not only of the dead but also of the bereaved families.

A funeral event was the last chance of rejoicing the life of a person who has died. It was the way of showing respect, gratitude and love to someone who passed away. Besides the celebration of life and death, a funeral event also serves as a 
means of bidding of the families' farewell. Celebrating funeral events varies from the funerary customs imposed by the different cultures, practices, religions, beliefs and tradition. Funeral service is one of the most important elements of a person's final arrangement. Preplanning a funeral eases the pain and burden and offers financial security for you and your loved ones and allows you to personalize your services.

Making funeral plans right after the death of an individual can be quite difficult because there is a little time to plan for the funeral and the family and friends of the deceased is at an uncontrollable emotional state. Another thing to consider is the financial concern. The payment for funeral service is due at the funeral, which means there will be little time for the family to cover the payment. This is considered a problem for most families because funeral service can be quite expensive in the Philippines. The price of the services and goods provided by the funeral homes are also affected by the economy's current status because the prices of these goods and services tend to vary and might increase overtime. Availing a prepaid funeral service gives us the benefit of accumulating the service while we still can afford it.

The study decides to have a comparative study of the availment of the funeral planning management service among Chinese and Filipino to observe the difference and similarities on the level of awareness, interest, the desire and actions of the two different cultures regarding the funeral planning management service. It also aims to determine the purchase intention of the two cultures. Through these efforts, the study intended to make a basis for developing an event strategy that would facilitate the acceptability of the funeral planning management service in the Philippines.

The AIDA model was used as a theoretical framework of this study. According to Rawal (2013), the AIDA model was basically derived from the acronym AIDA, which stands for attention, interest, desire and action. These four were considered as the common list of events that the consumer experienced when engaged with advertising. This was also considered as the steps in persuading the consumers to take action and buy the products. This model shows the effectiveness of advertising and marketing strategy since this model introduced the basic objectives that the advertising and marketing wished to meet.

Another framework was used in the study which is the Event-E-reference model framework for event management was a model framework that divides the series of event management into five domains: "Event Strategy", "Event Planning", "Event Realization", "Event Controlling" and "Project Management." Each domain is assigned special function. These functions are characterized by chronological and logical dependencies (Thomas, Hermes, \& Loos, 2008). This model can be used to support the execution of an event. It makes a recommendation of procedure for projects where events are planned and carried out. Although this model suggests a specific plan of procedure to practice, it still needs to adapt to the respective characteristics of different projects. The first domain in this Event-E-reference model framework for event management was the "event strategy". A strategy refers to the plan of action or policy designed to 
achieve a major or overall aim. This event strategy serves as the basic foundation for further planning.

The study aims to compare the availment of funeral planning management service among Chinese and Filipino in preparation of a service development package for a funeral event business. It seeks to answer the level of awareness on pre-paying, pre-planning, funeral rule, types of funeral, funeral cost, and payment for the funeral. The difference of the assessment between Chinese and Filipino were checked. Moreover, the problems were also looked upon.

This study will benefit the funeral stakeholders, which are the funeral planners, funeral chapels, funeral parlors, and funeral directors since this study aims to tackle the issue on availment of the funeral planning management services in the present condition. This study will give the funeral stakeholders a hint on how their services were currently recognized by their target market. This study also shows the decision making of both Chinese and Filipino markets toward the funeral planning management service that will help the funeral stakeholders in considering an innovation in their marketing strategy to improve the purchase intention rate of the Chinese and Filipino market. This study will also develop an event strategy about the availment of the funeral planning management service that can be adapted by the funeral stakeholders for their services,

This study will benefit the market of the funeral industry since the study will present the innovation in the funeral planning management service. This study will help the bereaved families to deal with a loss of a loved one. It will avoid the consumer's absurdity during the emotional stress in planning a funeral and also the market will be knowledgeable of the practices and regulations surrounding the funeral industry. This study can provide information that the future researchers can have as their reference for their study. The output of the study would greatly improve the outcome of related studies.

\section{Literature Review}

There was a complete satisfaction with the decision to pre-arrange funeral ceremonies as a revelation of Homesteaders policy owner. The NFDA (National Funeral Directors Association) study finds that some people who responded had their funeral event planned for them, and others stated that they are not interested or they do not want to think about having their funeral planned (Lambert, 2013). The study conducted by the Homesteaders' local market consistently showed that most consumers usually cannot name more than two funeral home names in their area and majority of them turns to the firm recommended by their friends or family. Funeral homes' lack of communication makes the consumers missed the opportunity to receive services that they would be highly satisfied. A more active pre-need marketing program provides education that transcends the mere existence of pre-need.

In the 2013 article by Lambert, he explained the awareness of cremation of the funeral homes. Nowadays, cremation becomes popular and it comes out to become like a funeral. According to the NFDA, there is only few of the 
consumers have their cremation without rituals while showing a preference for memorial ceremonies, even when cremation is desired. More than half of the people who responded that they are not aware that there are lots of options if they choose cremation as the method of disposition when planning a funeral. That is why NFDA grab the opportunity for pre-need as a way to educate and to inform the consumers.

As a response to the findings of the NFDAs and Homesteaders, Internet was used to easily give information to the target market about funeral event management. The data from the Internet can affect the consumer's frame of reference in making their decision regardless of the accuracy of it. Using the Internet, specifically the social media and reviews in some websites, it can help the potential consumer by providing information and sharing the experiences of the other consumers with the businesses to the people who do not have a personal experience and lack of understanding from families and friends. Thus, it is important to remember that market research is needed in gaining knowledge that are crucial to creating and communicating value to people in your service area.

The financial side of the funeral services is needed to know by the public. Awareness is an element of consumer protection law because it will somehow help the consumer understand any purchase fully. Family members or friends can support this way of thinking for those in emotional distress and help secure that the funeral arrangements are low-priced.

People often ignored getting a life plan or memorial plan. A memorial plan is a product that allows the plan holder to prepay funeral services at a low cost. It gives tremendous benefits and offers big cost savings. Assigning and transferring the plan to another person in case of need was a useful feature of this life plan. Assignment of plan is passing to a deceased person's benefit while transfer of plan ifs from the plan holder to another living person but this can lessen the benefits. Another benefit of the plan is when the plan holder dies without completing the payment, the full service benefit will be given. Funeral cost was arising and availing a memorial plan now can save you from the future raise of its cost. These plans can be paid fully, annually, semi-annually, quarterly, or on a monthly basis (Biolena, 2014).

Literatures presented were all relevant to the study of the availment of funeral planning management services among Chinese and Filipino. It tackled the funeral industry like characteristics of the funeral industry itself, the cost of the service rendered by the funeral homes, the innovations on the industries product and services, and the current state of the funeral industry. The present study focuses on the innovated service of the funeral providers unlike the focuses of the listed studies and literature, which are the general service of the funeral providers, the awareness in these services, and the funeral practices of the Filipino and Chinese society. 


\section{Methodology}

The descriptive method was used since the researchers aim to describe the natural behavior and characteristics towards the funeral planning management service of the two groups of respondents being studied. The descriptive method allowed the researchers to observe the present condition of the two groups of respondents in their natural environment by the acquisition of information from the respondents through questionnaires and analyzing it to formulate a conclusive statement relevant to the characteristics of the population.

The respondents of this study were 50 Filipino and 50 Chinese in Manila city. Every respondent must be middle aged up to senior citizens because the researchers believe that this age range possessed a mature perspective to discuss and decide about sensitive matters like death. Their maturity convinced the researchers that were qualified to evaluate and describe the present condition on the availment of the funeral planning management service.

\section{Results and Discussions}

Table 1. Summary of the Level of Awareness of the Respondents in terms of Funeral Conditions

\begin{tabular}{|l|l|l|l|l|l|l|}
\hline \multirow{2}{*}{ Criteria } & Chinese & Filipino & \multicolumn{2}{l|}{ Composite Value } \\
\cline { 2 - 7 } & WM & VI & WM & VI & WM & VI \\
\hline Prepaying & 3.02 & A & 3.47 & EA & 3.24 & A \\
\hline Preplanning & 3.12 & A & 3.45 & EA & 3.28 & EA \\
\hline Funeral Rule & 3.38 & EA & 2.90 & A & 3.14 & A \\
\hline Types of Funeral & 3.02 & A & 3.51 & EA & 3.26 & EA \\
\hline Funeral Cost for the & 3.30 & EA & 3.44 & EA & 3.37 & EA \\
\hline $\begin{array}{l}\text { Payment } \\
\text { Funeral }\end{array}$ & 3.05 & A & 3.56 & EA & 3.3 & EA \\
\hline Total & 3.15 & A & 3.39 & EA & 3.27 & EA \\
\hline
\end{tabular}

Table 1 presents the summary of the level of awareness of the respondents in terms of the funeral conditions. It revealed that the respondents were aware generally of the criteria presented. This looks very impressive due to the fact that they recognize the needs and the possibility of the existence of funeral management planning services. The Chinese respondents rated the funeral rule and funeral cost as extremely aware of the conditions. On the other hand, Filipinos rated funeral rule as aware while the rest of the criteria were all extremely aware. Overall, the Chinese respondents rated the conditions as aware while the Filipinos rated with extremely aware. Combining their rates, it was manifested with extremely aware.

Table 2. Summary of the Comparison of the Assessment of the Respondents

\begin{tabular}{|l|l|l|l|l|l|l|l|}
\hline \multirow{2}{*}{ Criteria } & \multicolumn{2}{|l|}{ Chinese } & \multicolumn{2}{|l|}{ Filipino } & \multirow{2}{*}{ T-Value } & \multirow{2}{*}{ VI } & \multirow{2}{*}{ Decision } \\
\cline { 2 - 5 } & WM & SD & WM & SD & & & \\
\hline Pre-Paying & 3.02 & 0.725 & 3.47 & 0.894 & 2.752 & S & Reject Ho \\
\hline Pre-planning & 3.12 & 0.725 & 3.45 & 0.931 & 1.967 & NS & Accept Ho \\
\hline Funeral Rule & 3.38 & 0.625 & 2.90 & 0.861 & 3.242 & S & Reject Ho \\
\hline Types of Funeral & 3.02 & 0.800 & 3.51 & 1.211 & 2.307 & S & Reject Ho \\
\hline Funeral Cost & 3.30 & 0.698 & 3.44 & 0.795 & 0.989 & NS & Accept Ho \\
\hline Paying for the Funeral & 3.05 & 0.817 & 3.56 & 1.122 & 2.610 & S & Reject Ho \\
\hline Total & 3.15 & 0.732 & 3.39 & 0.964 & 2.311 & S & Reject Ho \\
\hline
\end{tabular}


Table 2 presents the summary of the comparison of the assessment of the respondents. The underlying hypothesis being answered was the presence of significant differences between the responses of the Filipinos and Chinese. Generally, there was a significant difference between their responses after using the statistics of T-Value in comparing the two with 2.311, which is significant. Therefore, the null hypothesis was rejected. Only the criteria of pre-planning and funeral cost manifested that there were no significant differences between the two sets of respondents.

Table 3. The Problems Perceived by the Respondents

\begin{tabular}{|l|l|l|}
\hline Particulars & Frequency & Percentage \\
\hline CHINESE & \multicolumn{2}{|l|}{} \\
\hline Scam & 6 & 35 \\
\hline Funeral may not be stable & 4 & 24 \\
\hline Funeral providers may not be registered & 3 & 17 \\
\hline $\begin{array}{l}\text { Can they provide a funeral service if I die out of the } \\
\text { country? }\end{array}$ & 3 & 18 \\
\hline He may not receive the plan he is expecting to get & 1 & 6 \\
\hline TOTAL & 17 & 100 \\
\hline & \multicolumn{2}{|l|}{} \\
\hline FILIPINO & 8 & 36 \\
\hline Scam & 23 \\
\hline $\begin{array}{l}\text { The funeral homes may be closed by the time the plan is } \\
\text { needed }\end{array}$ & 5 & 23 \\
\hline The service may not be worth the value they are paying & 4 & 18 \\
\hline Unexpected expenses added onto prepaid plan & 3 & 14 \\
\hline Planning may be confusing & 2 & 9 \\
\hline TOTAL & 22 & 100 \\
\hline
\end{tabular}

Table 3 presents the problems that the respondents encountered. Both Chinese and Filipino respondents mentioned the scam as their most worried concern. Perhaps, this is because of the preneed companies history in the Philippines. Chinese respondents were too much worried about the stability and veracity of the insurance companies. Filipinos were worried about the quality of the services to be offered as they were looking for value for money concern.

Based on the findings of the study, the Filipino and Chinese respondents have an extreme level of awareness on funeral planning management service as to prepaying, pre-planning, funeral rule, types of funeral, funeral cost, and paying for the funeral. Respondents proved that there was significant difference with their level of awareness on the prepaying, funeral rules, types of funeral and paying for the funeral, yet there was no a significant difference with the funeral cost and pre planning in funeral planning management services. Consumers nowadays consider the advantages and disadvantages of availing these kinds of services for the value of their money. Based on the findings and conclusions presented, the following recommendations are suggested to the funeral providers that they may include funeral planning management services as part of their service offers. 


\section{References}

Aggarwal, P.Y. (2008). Descriptive Survey Research Method. International Journal of Transformations in Business Management, 1 (6), 1.

Castillo, L. V. (2012). House Urged to Probe Overpriced "Kabaong" and Funeral Services. $\quad$ Retrieved from http://www.congress.gov.ph/press/details.php?pressid=6328

Chidzel, M. (2011). Planning a Funeral. Retrieved from http://eventjuice.co.uk/planning-a-funeral/

Dagooc, E. (2010). Demand for Filipino Embalmers Growing. Retrieved from http://www.philstar.com/cebu-business/547704/demand-filipinoembalmers-growing

Dewar, A. (2013). Funeral Poverty: A Plan for Managing the Impact of Funeral Costs. Citizens Advice, 14-15.

Elbeck, M. (2008). Quantitative Methods Inquires. Journal of Applied Quantitative Methods, 3 (2), 167.

Gang, C. (2015). Mortuary Ritual Practices and Socio-Cultural Changes in Rural China. Anthropologist, 19 (1), 2.

Geronimo, G. (2012). Funeral Event Planners Ease the Pain and Burden Felt by the Bereaved. Retrieved from http://www.gmanetwork.com/news/story/280672/lifestyle/peopleandevents/ funeral-event-planners-ease-the-pain-and-burden-felt-by-the-bereaved

Gillespie, D., \& Defort, E. J. (2014). NFDA Consumer Awareness and Preferences Study Keeps Funeral Directors Give People What They Want. Memorial Business Journal, 5, 1-3.

Gobo, G., \& Mauceri S. (2014). An Interactional Approach. Constructing Survey Data, 208.

Kemp, E., \& Kopp, S. (2010). Have You Made Plans for that Big Day? Predicting Intentions to Engage in Funeral Planning. Journal of Marketing Theory and Practice, 18 (1), 81-84.

Lambert, D. (2013). Observation on Pre-need Insights from Homesteader's Life Company. 2013 Consumer Awareness and Preference Study, 1-2.

Miele, J. (2008). Filipino Funerals, Quite a "Send Off!" Retrieved from http://liveinthephilippines.com/content/filipino-funerals-quite-a-send-off/ 
Mirabi, V., Akbariyeh, H., \& Tahmasebifard, H. (2015). A Study of Factors Affecting on Customers Purchase Intention. Journal of Multidisciplinary Engineering Science and Technology, 2 (1), 267-268.

Page, J. (2015). Are Funeral Homes Best for the Last Journey of Life? Retrieved from https://www.academia.edu/11841803/Are_Funeral_Homes_Best_For_the_L ast_Journey_of_Life

Rawal, P. (2013). AIDA Marketing Communication Model: Stimulating a Purchase Decision in the Minds of the Consumers through a Linear Progression of Steps. IRC's International Journal Of Multidisciplinary Research In Social And Management Sciences, 1 (1), 37-41.

Ryan, K. (2013). Filipino Funeral Customs: Paying Homage to the Dead in the Philippines. Retrieved from http://blog.sevenponds.com/culturalperspectives/filipino-funeral-customs

Staab, J. (2014). Public Opinion Concludes Funeral Service has Dropped the Ball! Retrieved from http://blog.cremationsolutions.com/public-opinionconcludes-funeral-service-has-dropped-the-ball/2014/11/

Stellmach, W. (2013). Memorialization: So Many Ways, So Little Awareness. Management, 28.

Thomas, O., Hermes, B., \& Loos, P. (2008). Reference Model-Based Event Management. International Journal Of Event Management Research, 4, 4546. 